\title{
Long term treatment with theophylline increases malonyl dialdehyde plasma concentrations
}

\author{
P GODARD, J CHAINTREUIL, J BENSADOUN, G PARELON, A CRASTES DE PAULET, \\ FB MICHEL
}

From the Clinique de Maladies Respiratoires, Hôpital l'Aiguelongue, and Laboratoire de Biochimie A, Faculté de Médecine, Montpellier, France

ABSTRACT As theophylline is known to stimulate lipolysis and lipid mobilisation, plasma concentrations of malonyl dialdehyde were studied in asthmatic patients being treated with sustained release theophylline. Malonyl dialdehyde was assessed as malonyl dialdehyde like material (MDA-LM) by the thiobarbituric acid assay. In a kinetic study (eight patients) plasma MDA-LM concentrations were found to be significantly higher after 30 than after eight days' treatment or before treatment, but not significantly different after 90 than after 30 days. In a comparative study (29 patients and 29 healthy volunteers) the mean plasma MDA-LM concentration was shown to be very significantly higher in the asthmatic group. The results are probably explained by an effect of theophylline on lipid peroxidation, and the effect of long term treatment on plasma MDA-LM merits further investigation.

Theophylline is now widely used in the long term treatment of bronchial asthma. The introduction of appropriately formulated sustained release theophylline preparations has offered a potential improvement in theophylline treatment, allowing maintenance of plasma theophylline concentrations in the range $10-15 \mathrm{mg} / \mathrm{l}$ over long periods. The clinical adverse effects of such long term treatment remain to be evaluated. Theophylline has been shown to exert a stimulating effect on the lipolytic process in adipose tissue in vitro and to stimulate lipolysis and lipid mobilisation in vivo.' In this paper we report that long term treatment with theophylline increases the plasma concentration of malonyl dialdehyde.

\section{Methods}

Two sets of patients were studied. Firstly, we considered eight asthmatic patients who started treatment with sustained release theophylline and who

Address for reprint requests: Professor P Godard, Clinique des Maladies Respiratoires, Hôpital 1 Aiguelongue, Avenue du Major Flandre, 34059 Montpellier Cedex, France.

Accepted 18 October 1983 were followed for three months (ages 18-31, mean 25 years). They had mild bronchial asthma, with continuing airway obstruction $\left(\mathrm{FEV}_{1} \mathbf{7 0} \cdot 2 \%\right.$ (SD $2 \cdot 1 \%$ ) predicted), which could be partially reversed by inhaled salbutamol. None received corticosteroids, and $\beta$ agonist drugs were used by aerosol-only if necessary and less than four times daily. Among these patients six had never received theophylline treatment before. The dose was adjusted to obtain serum concentrations of 8-15 $\mathrm{mg} / \mathrm{l}($ mean $(\mathrm{SEM}) 10 \cdot 2(0 \cdot 3) \mathrm{mg} / \mathrm{l})$ and maintained during the three months of the study. This part will be referred to as the kinetic study.

Secondly, we measured plasma malonyl dialdehyde concentrations in a group of 29 asthmatics who had received sustained release theophylline for at least three months (range 3-16 months, mean (SEM) 6.2 (0.9) months). These asthmatic patients had mild bronchial asthma and were mainly treated with theophylline (10 patients received steroids by aerosol, five others received ketotifen by mouth, and 15 received $\beta$ adrenergic drugs by aerosol as needed-less than four times a day). Mean plasma theophylline concentrations were 10.6 (SEM 0.2) $\mathrm{mg} / \mathrm{l}$. Twenty nine healthy volunteers, matched for age and sex, were also studied as a control group. This part will be referred to as the comparative study. 
Malonyl dialdehyde was assessed as malonyl dialdehyde like material (MDA-LM) by the thiobarbituric acid assay, according to the method of Smith et al. ${ }^{2}$ Briefly, $200 \mu \mathrm{l}$ of plasma was treated with an equal volume of perchloric acid and heated for five minutes at $100^{\circ} \mathrm{C}$ to precipitate the proteins. After centrifugation at $3000 \mathrm{~g}$ for 10 minutes, $300 \mu \mathrm{l}$ of sample supernatant was added to $300 \mu$ lof thiobarbituric acid and perchloric acid aqueous solution $(0.66 \%$ and $1.15 \% \mathrm{v} / \mathrm{v}$ respectively). The colour reaction was achieved by heating for 15 minutes at $100^{\circ} \mathrm{C}$. A blank was made for each plasma specimen under the same conditions, except that thiobarbituric acid was not added to the reaction medium. Absorbance was measured at $532 \mathrm{~nm}$ and corrected for the absorbance of the blank, and the MDA-LM was determined by reference to a standard curve.

In the kinetic study blood samples were taken before treatment and after eight days, one month, and three months of treatment. Two patients discontinued theophylline treatment at the third month; in these patients blood samples were taken again 15 days and 30 days after they had stopped the treatment.

\section{Results}

\section{KINETIC STUDY}

After eight days of treatment with sustained release theophylline plasma MDA-LM concentrations had risen slightly in seven of the eight patients $(p<$ $0 \cdot 05$ ) (fig). After 30 days plasma MDA-LM concentrations were significantly higher than those observed at eight days or before the start of treatment ( $p<0.01)$ (Wilcoxon signed rank sum test). After 90 days plasma MDA-LM concentrations had risen further in five patients and fallen in three, and for the group as a whole the concentrations were not significantly different from those observed at 30 days. In the two patients who discontinued treatment MDA-LM plasma concentrations had fallen after 15 days and had fallen further after 30 days. In the kinetic study group four patients had high MDA-LM concentrations (above $3 \mathrm{nmol} / \mathrm{ml}$ ) before treatment (fig); two of these had been pregnant within two months of the study and two had received theophylline in the previous two months, using non-sustained-release tablets daily by mouth.

\section{COMPARATIVE STUDY}

The plasma MDA-LM concentration was significantly higher in the asthmatic group than in the control group $(3 \cdot 10($ SEM $0 \cdot 10)$ and $2 \cdot 52(0 \cdot 10)$ $\mathrm{nmol} / \mathrm{ml}$ respectively: $\mathrm{p}<0.001$, Student's $t$ test).

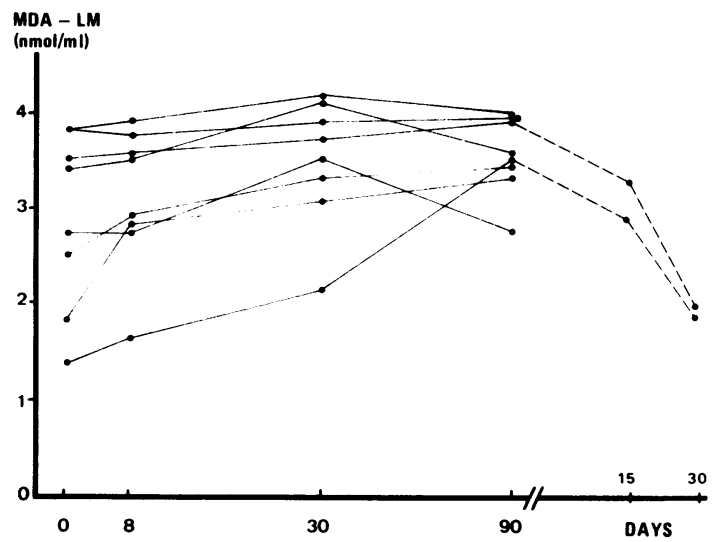

Plasma concentrations of malonyl dialdehyde like material $(M D A-L M)$ in eight patients beginning sustained release theophylline treatment and evolution of MDA-LM plasma concentrations in two patients who discontinued the treatment after three months.

\section{Discussion}

The thiobarbituric acid assay has been widely used as an index of lipid peroxidation in plasma. ${ }^{34}$ On the other hand, this method has sometimes been said to measure platelet aggregatory function through malonyl dialdehyde production. ${ }^{2}$ In a previous study $^{5}$ we reported that plasma MDA-LM could be distinguished in two fractions, on the basis of the hydrophobic and hydrophilic features of each fraction. Performing an extraction of plasma lipids by Folch's method, ${ }^{6}$ we showed that $74.8 \%$ (SEM $4.3 \%$ ) of total MDA-LM was found in the extractable lipid fraction and was thus probably related to lipoperoxides. The remainder was non-extractable native malonyl dialdehyde. This chemical species is released during the oxidation of arachidonic acid by the cyclo-oxygenase and thromboxane synthetase pathway. Certain authors consider it to be an indicator of prostaglandin synthesis, especially of synthesis by platelets. ${ }^{2}$

The increase in plasma thiobarbituric acid reactive malonyl dialdehyde that follows treatment with sustained release theophylline can therefore be explained by either or both of the following factors: (1) an enhancement of platelet aggregation associated with an activation of platelet thromboxane synthesis; (2) a rise in polyunsaturated fatty acid peroxidation.? The first mechanism is rather unlikely since theophylline is supposed to enhance the cyclic adenosine monophosphate (cAMP) content of the cells, which is known to inhibit platelet aggregation. An effect on lipid peroxidation is the most probable explanation for our results. Lipid peroxidation is 
observed in various physiological and pathological processes, such as pregnancy and toxaemia of pregnancy, ${ }^{3}$ radiation damage, vitamin $E$ insufficiency, and aging. ${ }^{58}$ These associations of lipid peroxidation with pathological conditions do not necessarily imply that the process is directly concerned in pathogenesis.9 The effect of long term theophylline treatment on plasma MDA-LM, however, raises a question and deserves further investigation.

We are indebted to Professor M Turner-Warwick, Cardiothoracic Institute, London, for her advice on the manuscript.

\section{References}

1 Arnman K, Carlstrom S, Thorell JI. The effect of norepinephrine and theophylline on blood glucose, plasma FFA, plasma glycerol and plasma insulin in normal subjects. Acta Med Scand 1975;197:271-4.

${ }^{2}$ Smith JB, Ingerman CM, Silver MJ. Malon dialdehyde formation as an indicator of prostaglandin production by human platelets. $J$ Lab Clin Med 1976;88:167-72.

${ }^{3}$ Ishihara M. Studies on lipoperoxides of normal pregnant women and of patients with toxemia of pregnancy. Clin Chim Acta 1978;84:1-9.

${ }^{4}$ Takeuchi N, Lanaka F, Katayama Y, Matsumura K, Yamamura Y. Effects of alpha tocopherol on thiobarbituric acid reactive substances in serum and hepatic subcellular organelles and lipid metabolism. Exp Gerontol 1976;11:179-81.

${ }^{5}$ Poubelle P, Chaintreuil J, Bensadoun J, Blotman F, Simon L, Crastes de Paulet A. Plasma lipoperoxides and aging. Biomedicine 1982;36:164-6.

${ }^{6}$ Folch J, Lees M, Sloane Stanley GH. A simple method for the isolation and purification of total lipids from animal tissues. J Biol Chem 1957;226:497-509.

${ }^{7}$ Dahle LK, Hill EG, Holman RI. The thiobarbituric acid reaction and the autoxidation of polyunsaturated fatty acid methyl esters. Arch Biochem Biophys 1962;98:258-61.

${ }^{8}$ Kernogou JF, Bernard P, Braquet M, Rocquet G. Effect of whole body gamma irradiation on lipid peroxidation in rat tissues. Biochimie 1981;63:555-9.

${ }^{9}$ Barber AA, Bernheim F. Lipid peroxidation: its measurement, occurrence and significance in animal tissues. In: Strehler BI, ed. Advances in Gerontological Research. Vol 2. New York: Academic Press, 1967:355. 